\title{
Perancangan dan Implementasi Sistem Informasi Rekam Medis (Studi Kasus: Puskesmas Onekore)
}

\author{
Andy Ahmad ${ }^{1}$, Ferdinandus Lidang Witi ${ }^{2}$ \\ Sistem Informasi, Fakultas Teknologi Informasia, Universitas Flores, Ende, Indonesia \\ Program Studi, Fakultas, Nama Institusi, Kota, Indonesia \\ Email: andyneo4894@gmail.com, ferdylidang2017@gmail.com
}

\begin{abstract}
The medical record information system is an information system that manages patient data and documents containing patient identities, examination results, payments and other services that have been provided to patients. The existing medical record information system at the Onekore Health Center is still processed manually, namely using a ledger for recording and also takes up a lot of storage space. So that patient service at the Onekore Health Center becomes less effective and efficient. Therefore, we need a concept for processing patient medical record data by considering the time efficiency and safety required for the patient data collection process. The purpose of this study is to build a computerized medical record information system in order to provide convenience for medical officers in providing health services to patients to be more effective and also easier in making reports. This medical record information system is designed using the Microsoft Visual Studio programming language and MySQL as the database. The research method used in this research is descriptive qualitative method. While the testing technique uses the Blackbox testing method.
\end{abstract}

Keywords: Information Systems, Medical Records, Microsoft Visual Studio, MySQL, Blackbox testing

\begin{abstract}
ABSTRAK
Sistem informasi rekam medis merupakan sistem informasi yang mengelola data pasien dan dokumen yang berisi identitas pasien, hasil pemeriksaan, pembayaran dan pelayanan lain yang telah diberikan kepada pasien. Adapun sistem informasi rekam medis yang ada pada Puskesmas Onekore pengolahannya masih dengan cara manual, yaitu mengunakan buku besar untuk pencatatan dan juga memakan banyak tempat penyimpanan. Sehingga pelayanan pasien pada Puskesmas Onekore menjadi kurang efektif dan efisien. Oleh karena itu, diperlukan suatu konsep pengolahan data rekam medis pasien dengan mempertimbangkan efisiensi waktu dan keamanan yangb dibutuhkan untuk proses pendataan pasien. Tujuan penelitian ini adalah untuk membangun sebuah sistem informasi rekam medis secara komputerisasi guna memberikan kemudahan bagi petugas medis dalam memberikan pelayanan kesehatan kepada pasien agar lebih efektif dan juga lebih mudah dalam pembuatan laporan. Sistem informasi rekam medis ini dirancang dengan menggunakan bahasa pemrograman Microsoft Visual Studio dan MySQL sebagai databasenya. Metode penelitian yang digunakan dalam penelitian ini, yaitu metode kualitatif deskriptif. Sedangkan teknik pengujian menggunakan metode Blackbox testing.
\end{abstract}

Kata Kunci:Sistem Informasi, Rekam Medis, Microsoft Visual Studio, MySQL, Blackbox testing

\section{Pendahuluan}

\subsection{Latar Belakang}

Dengan berkembangnya teknologi informasi dan sistem informasi yang sangat pesat, telah membuat hampir semua bidang kehidupan tidak dapat terhindar dari pengguna perangkat komputer. Penggunaan komputer yang sering digunakan dalam bentuk yang berbeda, seperti dalam bidang pendidikan, hiburan, komunikasi, ekonomi, bisnis dan kesehatan. Salah satu sumber informasi dalam bidang kesehatan yang paling berpengaruh adalah pencatatan rekam medis pada puskesmaspuskesmas yang berada di berbagai pelosok Indonesia dan salah satunya adalah Puskesmas Onekore.

Puskesmas Onekore terletak di Kabupaten Ende dan masuk dalam wilayah kerja Kelurahan Onekore, yang berada di Kecamatan Ende Tengah. 
Puskesmas Onekore belum mempunyai sistem informasi pencatatan rekam medis secara komputerisasi sehingga memperlambat sistem kerja petugas medis dan memakan waktu pasien yang datang berobat.

Rekam medis merupakan keterangan baik tertulis maupun yang terekam tentang identitas, anamnes, penentuan fisik, laboratorium dan diagnosa segala pelayanan dan tindakan medis yang diberikan kepada pasien baik yang di rawat inap, rawat jalan maupun pelayanan gawat darurat [1].

Informasi yang didapatkan saat melakukan penelitian langsung ke Puskesmas Onekore bahwa penduduk yang menggunakan jasa pelayanan kesehatan pada Puskesmas Onekore adalah penduduk yang terdapat di Kelurahan Onekore dan juga penduduk diluar wilayah Kelurahan Onekore yang setiap hari datang berobat. Rata-rata jumlah pasien yang datang berobat berkisar sekitar 30-40 orang perhari yang tercatat pada rekapan register kunjungan loket. Untuk penduduk diluar wilayah Kelurahan Onekore yang datang berobat di Puskesmas Onekore harus didata terlebih dahulu sebagai pasien baru.

Pencatatan rekam medis di Puskesmas Onekore masih dilakukan secara konvensional, yaitu dengan mencatat pada buku besar. Dengan jumlah pasien yang datang berobat sekitar 40 orang perhari menyebabkan pengelolaan data pasien menjadi tidak efisien. Petugas medis kesulitan dalam mencari data pasien lama karena data terlalu menumpuk dan harus membuka buku rekam medis satu persatu. Biasanya, ada pasien yang kehilangan kartu berobat petugas loket harus membuat kartu berobat yang baru. Masalah lain yang sering terjadi yaitu tersitanya waktu pasien untuk mendapatkan pemeriksaan kesehatan karena harus menunggu petugas medis mengumpulkann kartu berobat sebelum diserahkan ke poliklinik.

Untuk mengatasi permasalahan-permasalahan tersebut, diperlukan sistem informasi rekam medis pasien berbasis komputer. Dengan adanya sistem informasi yang berbasis komputer dapat meningkatkan kualitas pelayanan kesehatan dari petugas Puskesmas Onekore terhadap pasien yang datang berobat setiap harinya dan membantu petugas medis dalam mengelola data rekam medis pasien serta dalam pembuatan laporan jadi lebi mudah dan efektif.

\subsection{Kajian Penelitian Relevan}

1. Sistem Informasi Rekam Medis Rawat Jalan Dan Pemeriksaan Penunjang Diagnosa Berbasis Website (Studi Kasus: Rumah Sakit Khusus Bedah Klinik Sinduadi, Mlati, Sleman, Yogyakarta), penelitian ini dilakukan oleh Vindra Yudha Hendrawan, Sugeng Winardi, Herison Surbakti mahasiswa Fakultas Sains dan Teknologi Program Studi Sistem Informasi.

2. Pembuatan Sistem Informasi Rekam Medis Terpadu Dalam Upaya Meningkatkan Pelayanan
Rumah Sakit Jiwa Tampan Prov. Riau, Penelitian ini dilakukan oleh Irwandi Tanjung, Darmanta Sukrianto Mahasiswa Manajemen Informatika, Amik Mahaputra Riau.

3. Sistem Informasi Pelayanan Kesehatan Berbasis Web di Puskesmas., penelitian ini dilakukan oleh Pradikta Andrianto, Agus Nursikuwagus, ST.,MT.,MM.,MOS. mahasiswa Program Studi Sistem Informasi Universitas Komputer Indonesia Bandung, Jawa Barat 40132, Indonesia.

4. Pembuatan Sistem Informasi Rekam Medis Pada Puskesmas Jomin Berbasis Web, penelitian ini dilakukan oleh Agung Prasetyo, Mohammad Syamsul Azis.

5. Aplikasi Sistem Rekam Medis Di Puskesmas Kelurahan Gunung, penelitian ini dilakukan oleh Sita Syifani, Ardiansyah Dores.

\section{Metode Penelitian}

\subsection{Metodologi Perancangan Perangkat Lunak}

Pada penelitian ini metode pembuatan aplikasi yang digunakan adalah Waterfall. Metode ini melakukan pendekatan secara sistematis dan berurutan yang dimulai dari tingkatan sistem tertinggi dan berlanjut ketahap analisis, desain, pengkodean, penguji dan pemeliharaan. Kelebihan dari metode ini adalah terstruktur, dinamis, dan sequintal [2].

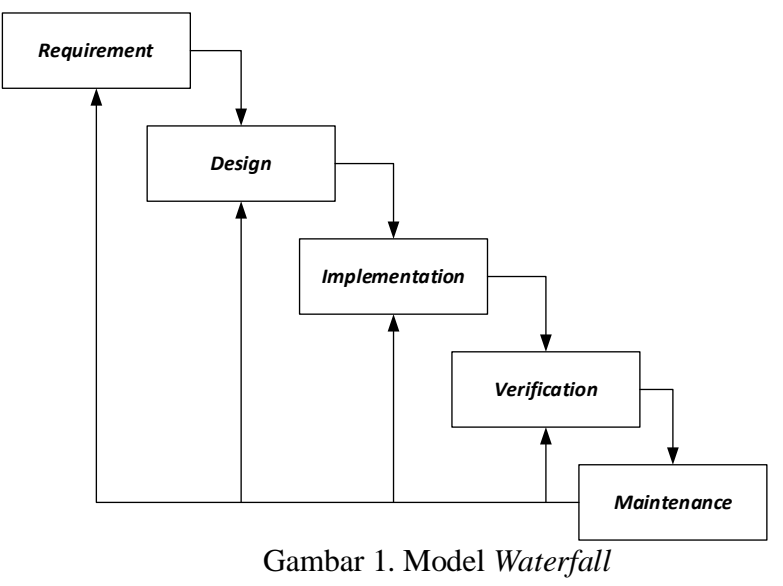

Berikut ini adalah penjelasan dari beberapa tahapan proses model waterfall:
1. Requirements
Proses pencarian kebutuhan diintensifkan dan difokuskan pada software. Untuk mengetahui sifat dari program yang akan dibuat maka para software engineer harus mengerti tentang domain informasi dari software.
2. Design
Proses ini digunakan untuk mengubah kebutuhan diatas menjadi representase kedalam bentuk "blueprint" software 
sebelum coding dimulai. Desain harus Adapun tahapan-tahapan kegiatan penelitian yang dapat mengimplementasikan kebutuhan peneliti lakukan:

yang telah disebutkan pada tahap sebelumnya.

3. Implementation

Agar dapat dimengerti oleh mesin dalam hal ini Komputer, maka desain yang tadi harus diubah bentuknya menjadi bentuk yang dapat dimengerti oleh mesin, yaitu mengubah kedalam bentuk bahasa pemrograman melalui proses coding.

4. Verification

Segala sesuatu yang telah dibuat haruslah diuji cobakan demikian juga dengan software. Semua fungsi-fungsi software harus diuji cobakan agar software tersebut bebas dari error dan hasilnya juga harus benar-benar sesuai dengan kebutuhan yang sudah didefinisikan sebelumnya,

5. Maintenance

Pemeliharaan suatu software sangalah penting, karena software yang dibuat tidak selamanya seperti itu. Apabila dijalankan mungkin saja masih terdapat error kecil yang belum ditemukan sebelumnya atau ada penambahan fiturfitur yang belum ada pada software tersebut.

\subsection{Tahap-tahap penelitian}

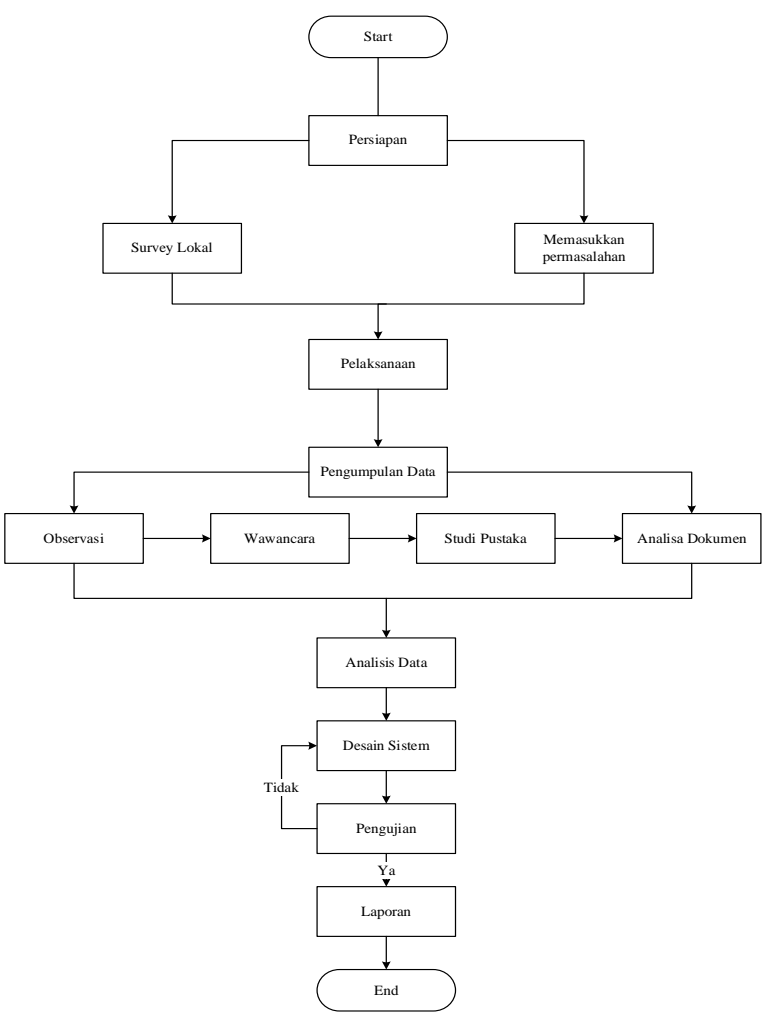

Gambar 2. tahap - tahap penelitian a. Persiapan

Pada tahap ini peneliti melakukan survey awal ke Puskesmas Onekore guna untuk mengumpulkan informasi yang berkaitan dengan penelitian yang akan peneliti lakukan. Berdasarkan informasi yang peneliti dapatkan, maka peneliti mengangkat permasalahan yang ditemui dilapangan untuk diteliti dan memberikan solusi untuk mengatasi masalah tersebut. Selain itu peneliti juga melakukan wawancara awal terhadap petugas Puskesmas Onekore yang berkaitan dengan masalah yang peneliti angkat dalam penelitian ini.

b. Pelaksanaan

Pada tahap ini peneliti akan melakukan pengumpulan data dengan cara observasi, wawancara, studi pustaka dan analisis dokumen guna memperoleh informasi serta menjelaskan cara penggunaan Sistem Informasi Rekam Medis Kepada petugas Puskesmas Onekore.

c. Anallisis Data

Setelah melakukan pengumpulan data, selanjutnya mengalisis data maka akan memperoleh informasi yang dapat digunakan sebagai penyelesaian permasalah.

d. Desain Sistem

Setelah melakukan analisis data, penulis merancang desain sistem dengan menggunakan Usecase Diagram, Context Diagram, Data Flow Diagram, dan Relasi tabel.

e. Pengujian

Dari hasil desain perangkat lunak akan direalisasikan satu program. Dimana setiap unit akan program akan diuji terlebih dahulu sebelum dikirim ke pengguna. Jika pengujiannya tidak berhasil maka akan melakukan desain ulang sistem tetapi jika berhasil akan meanjutkan ke tahap pelaporan.

f. Pelaporan

Setelah melakukan pengumpulan data serta menjelaskan cara penggunaan Sistem Informasi Rekam Medis dan analisis data maka akan diperoleh informasi yang dapat digunakan untuk sebagai penyelesaian permasalahan tersebut.

\subsection{Jenis dan Metode Pengumpulan Data}

Adapun metode pengumpulan data yang digunakan pada penelitian ini yakni:

1) Observasi

Metode Observasi adalah metode pengumpulan data dengan cara mengamati dan memperlihatkan objek penelitian baik secara langsung maupun tidak langsung serta mengadakan pencatatan tentang hasil pengamatan tersebut secara sistematis. Kegiatan

DOI: $10.54259 /$ satesi.v1i2.26

Lisensi: Creative Commons Attribution 4.0 International (CC BY 4.0) 
observasi yang dilakukan di Puskesmas Onekore dengan cara mengamati bagaimana proses Rekam Medis. Observasi dilakukan untuk mengetahui kualitas perangkat lunak pada aspek reliability dan efficiency.

2) Wawancara

Wawancara dilakukan dengan. petugas Puskesmas Onekore. Wawancara bertujuan untuk mengetahui informasi mengenai permasalahan yang terjadi, sistem yang dibutuhkan sebagai solusi permasalahan tersebut dan kebutuhan sistem.

3) Studi Pustaka

Studi Pustaka adalah salah satu metode pengumpulan data dengan cara mencari referensi teori yang relevan dengan kasus atau permasalahan yang ditemukan seperti buku, jurnal, atau skripsi.

4) Analisa Dokumen

Pengumpulan data ini dengan cara mencari data mengenai dokumendokumen dengan menggunakkan bukti yang akurat dari berbagai sumber informasi yang berhubungan dengan topik pembahasan yang akan di analisis.

\subsection{Analisa Sistem}

Analisa sistem didefinisikan sebagai penguraian dari suatu sistem informasi yang utuh kedalam bagianbagian komponennya dengan maksud untuk mengidentifikasi dan mengevaluasi permasalahanpermasalahan, kesempatan-kesempatan, hambatanhambatan yang terjadi dan kebutuhan-kebutuhan yang diharapkan sehingga dapat diusulkan perbaikanperbaikannya[3].

\section{a. Analisa Sistem Yang Berjalan}

Alur pelayanan kesehatan yang ada pada Puskesmas Onekore, dimana pasien baru maupun pasien lama yang datang berobat di Puskesmas harus membawa kartu berobat. Untuk pasien baru harus menunjukan identitas/KIS kepada petugas loket untuk melakukan registrasi dan membuat kartu berobat baru. Sedangkan untuk pasien lama hanya menunjukan kartu berobat saja yang sudah ada untuk mencari data rekam medis dan mencatat pada buku register harian kunjungan loket. Selesai mengisi data rekam medis, pasien langsung diarahkan kepoli tujuan untuk melakukan pemeriksaan. Setelah pasien mendapatkan pelayanan pemeriksaan kesehatan pada poli, pasien langsung menuju ke apotek puskesmas untuk mengambil obat sesuai resep yang diberikan petugas poli dan setelah menerima obat pasien langsung pulang.

Analisa Sistem yang berjalan pada Puskesmas Onekore digambarkan dalam bentuk Flowchart, sebagai berikut:

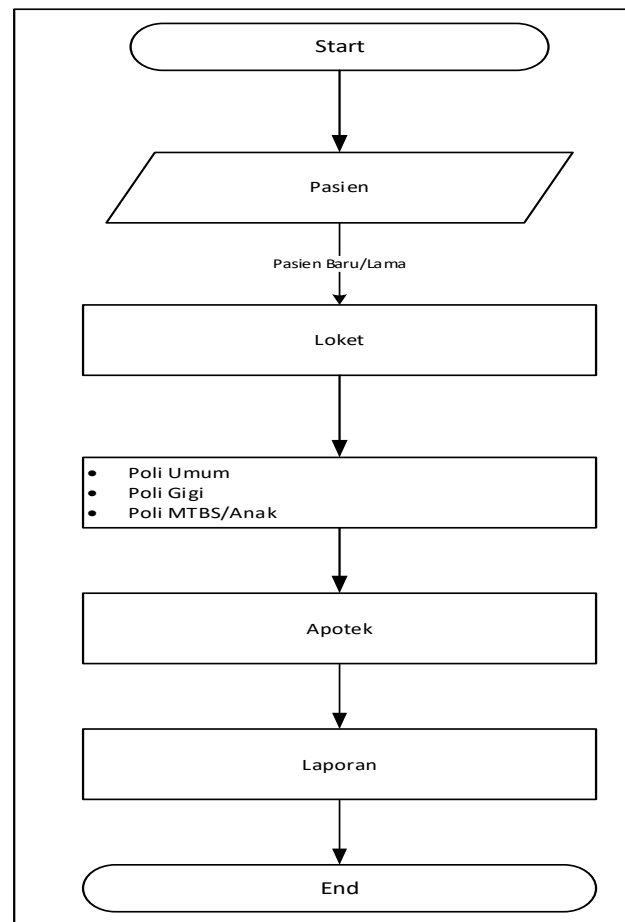

Gambar 3. Analisa Sistem Yang Berjalan

\section{b. Analisa Sistem Yang Diusulkan}

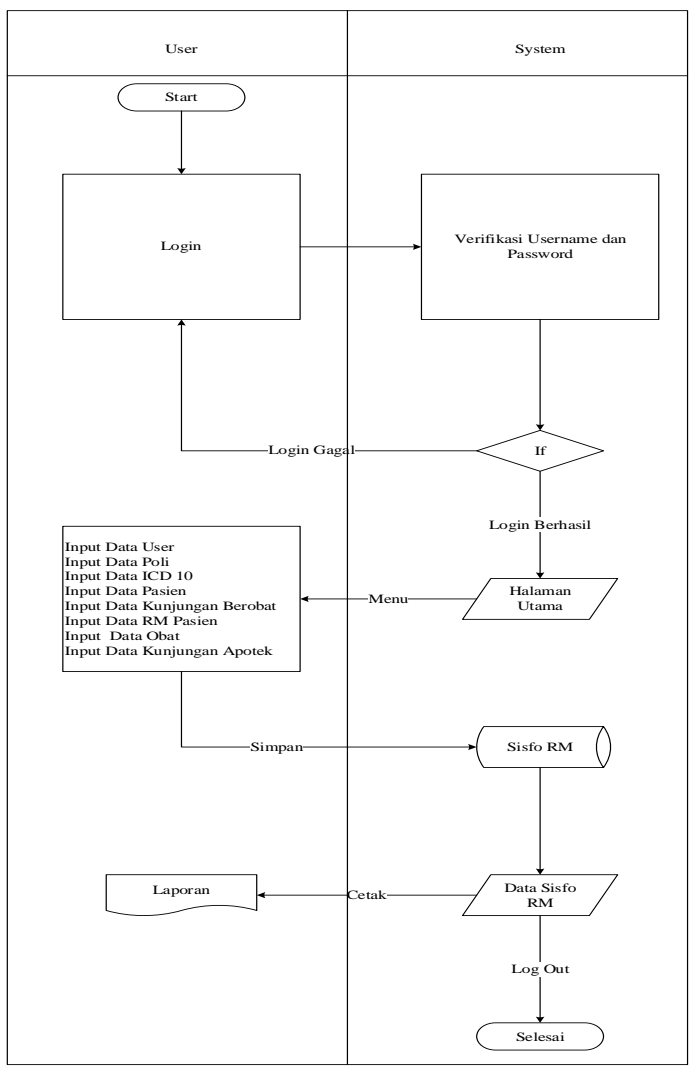

Gambar 4. Analisa Sistem Yang Diusulkan

\subsection{Analisis Kebutuhan}

Pengembangan sistem informasi memerlukan analisis mengenai alasan timbulnya gagasan untuk mengembangkan sistem informasi. Analisis dilakukan untuk melihat berbagai komponen yang berjalan 
meliputi hardware, software, jaringan, dan sumber daya manusia. Analisis kebutuhan sistem harus mendefinisikan kebutuhan sistem yang spesifik yaitu input, output, process, sumber data yang ditangani dan pengendalian[4].

\section{a. Analisis Kebutuhan Hardware}

Perangkat keras yang saya gunakan untuk merancang sistem informasi rekam medis pada Puskesmas Onekore, terdiri dari Personal komputer (Laptop) dengan Processor Intel Celeron@CPU N3060, Intel HD Graphics, 2 GB DDR3 L Memory, 500 GB HDD

\section{b. Analisis Kebutuhan Software}

Perangkat lunak yang saya gunakan untuk merancang sistem informasi rekam medis pada Puskesmas Onekore, terdiri dari Sistem Operasi Microsoft Windows 10, Web browser (Google Chrome), XAMPP sebagai server yang berdiri sendiri (localhost), MySQL sebagai database server dan Apache sebagai web server, Bahasa pemrograman 2.7 Microsoft Visual Studio 2010, Micrososft Visio 2013 untuk membuat dokumen flow dan sistem flow.

\subsection{Desain Sistem}

Desain sistem pada penelitian ini menggunakan fungsi yang berbeda.

usecase diagram, contex diagram dan Data Flow Diagram.

\section{a. Usecase Diagram}

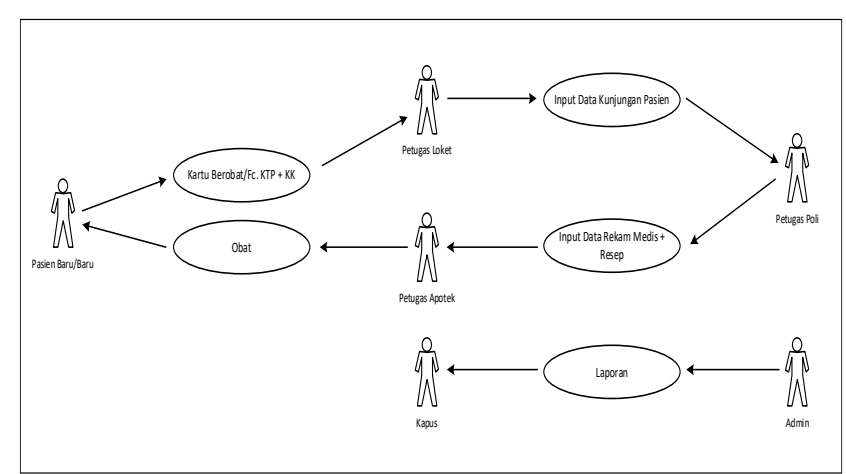

Gambar 5. Usecase Diagram

\section{b. Context Diagram}

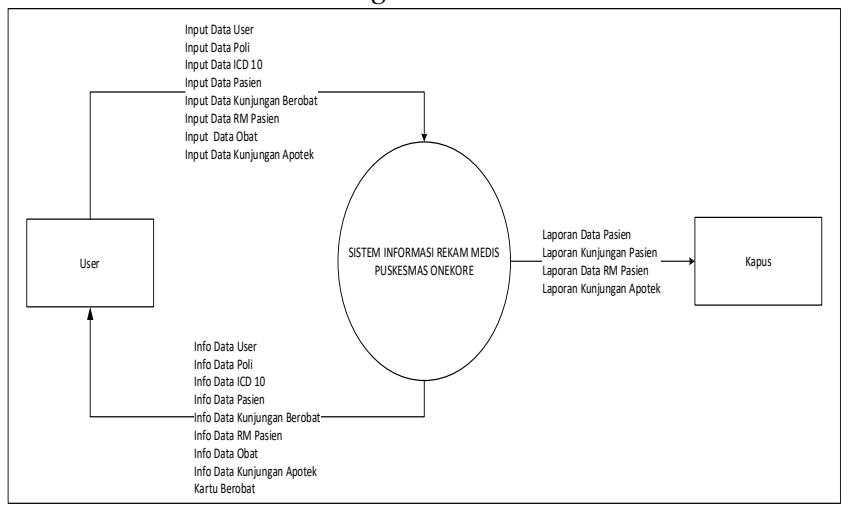

Gambar 6. Context Diagram

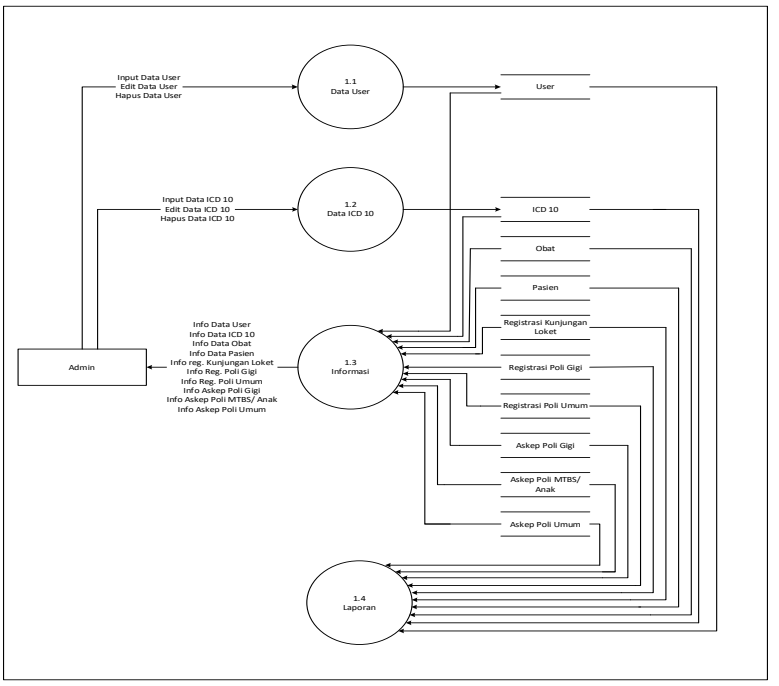

Gambar 7. Data Flow Diagram

\subsection{Perancangan Database}

Perancangan database dalam membangun sistem informasi rekam medis pada Puskesmas Onekore terdiri atas beberapa tabel yang mempunyai struktur dan Perancangan tabel yang diterapkan sebagai berikut: 


\section{Hasil dan Pembahasan}

\subsection{Perancangan Antarmuka}

a. Rancangan Antarmuka Menu Login

Rancangan Antarmuka Form Login digunakan untuk menginputkan username dan password agar dapat mengakses sistem. Bentuk rancangan seperti gambar di bawah ini:

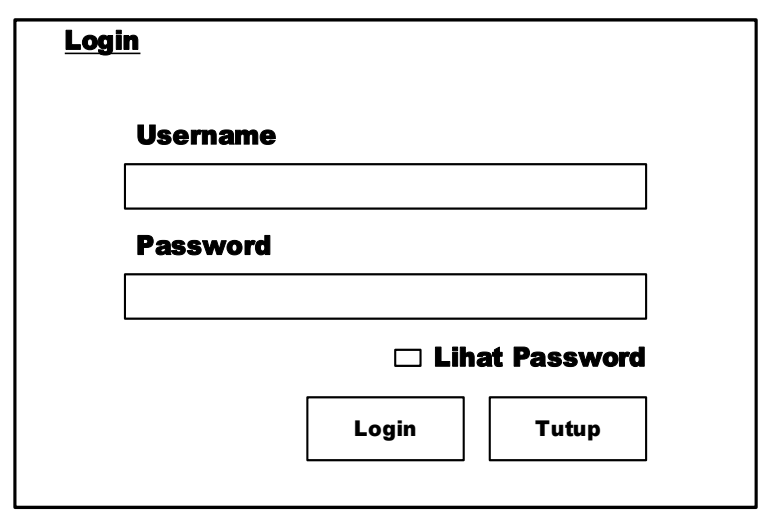

Gambar 9. Rancangan Antarmuka Menu Login

b. Rancangan Antarmuka Menu Utama

Rancangan Antarmuka Form Menu utama digunakan untuk menampilkan Menu utama setelah melakukan login.

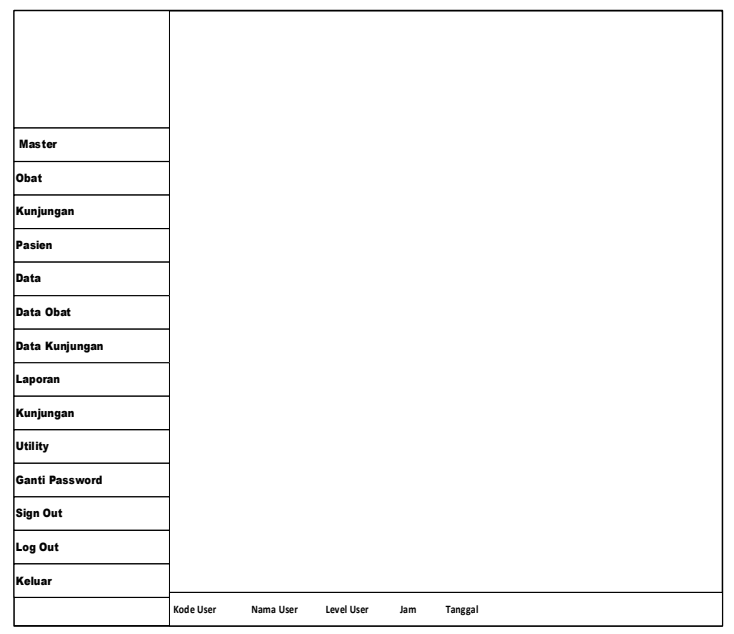

Gambar 10. Rancangan Antarmuka Menu Utama

c. Rancangan Antarmuka Master User

Rancangan Antarmuka Master User digunakan untuk menampilkan data data user.

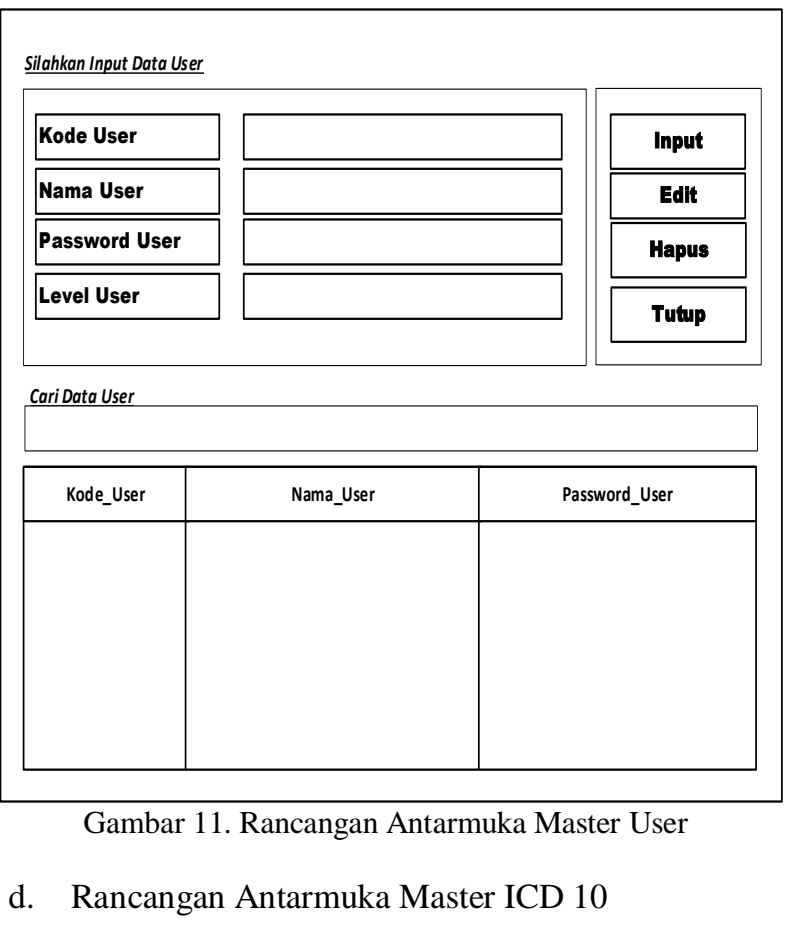

Rancangan Antarmuka Master ICD 10 untuk menampilkan data data ICD 10.

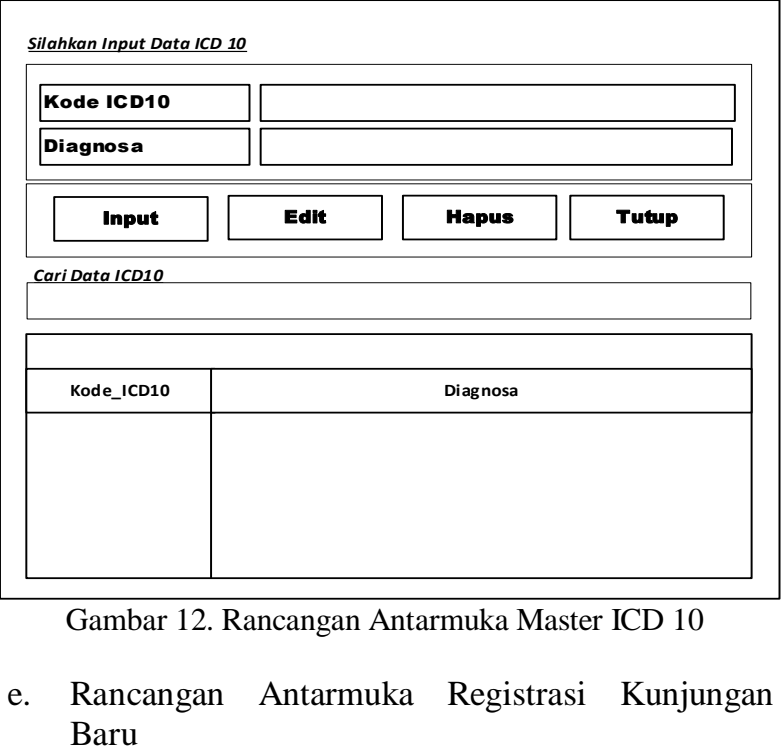

Rancangan Antarmuka Registrasi Kunjungan Baru digunakan untuk menampilkan data data pasien yang melakukan kunjungan baru. 


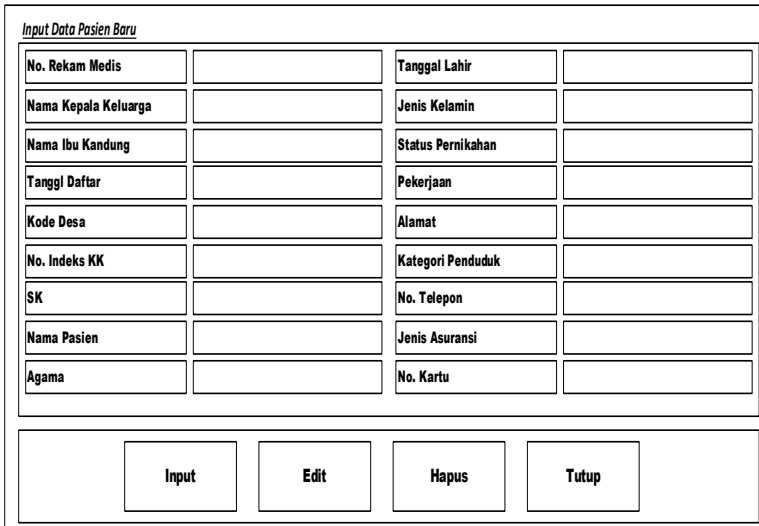

Gambar 13. Rancangan Antarmuka Registrasi Kunjungan Baru

\section{f. Rancangan Antarmuka Register} Pendaftaran

Rancangan Antarmuka Register Loket Pendaftaran digunakan untuk menampilkan data register loket pendftaran.

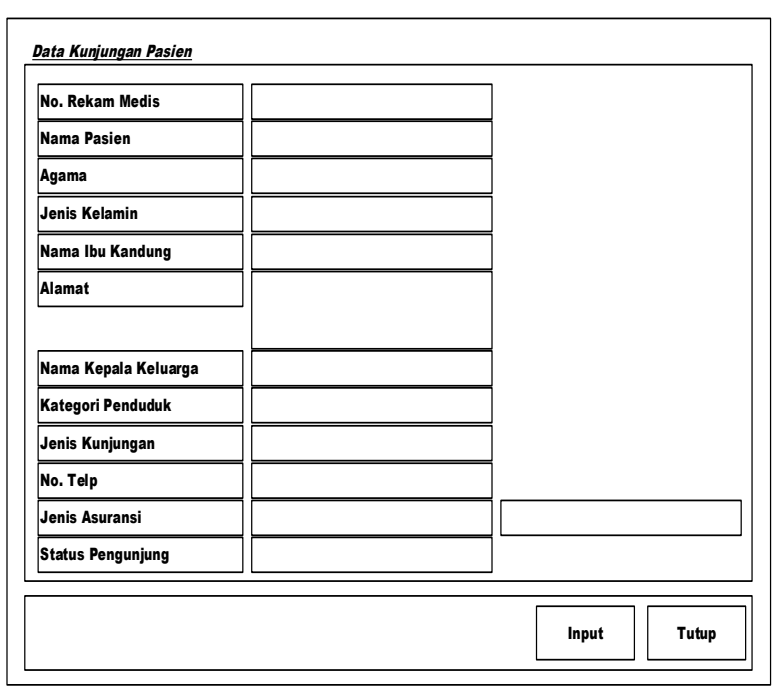

Gambar 14. Rancangan Antarmuka Register Loket

$$
\text { Pendaftaran }
$$

g. Rancangan Antarmuka Master Obat

Rancangan Antarmuka Master Obat digunakan untuk menampilkan data data obat.

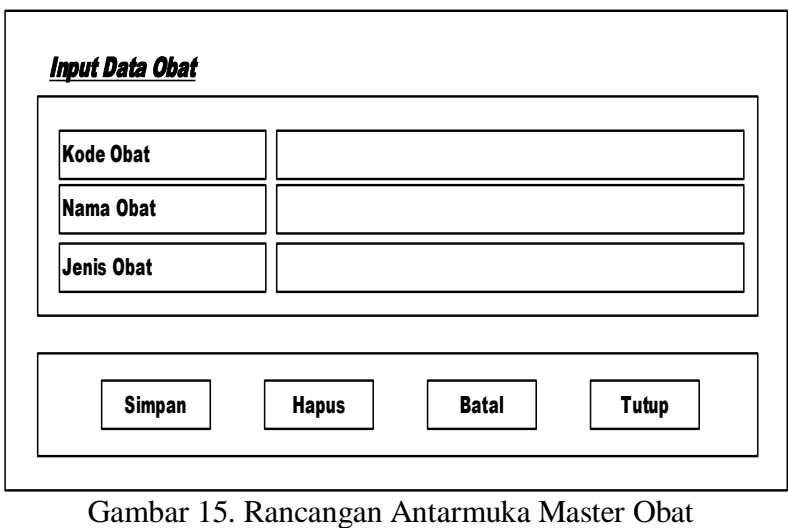

h. Rancangan Antarmuka Poli Umum

Rancangan Antarmuka Poli Umum digunakan untuk menampilkan data data yang ada pada poli umum

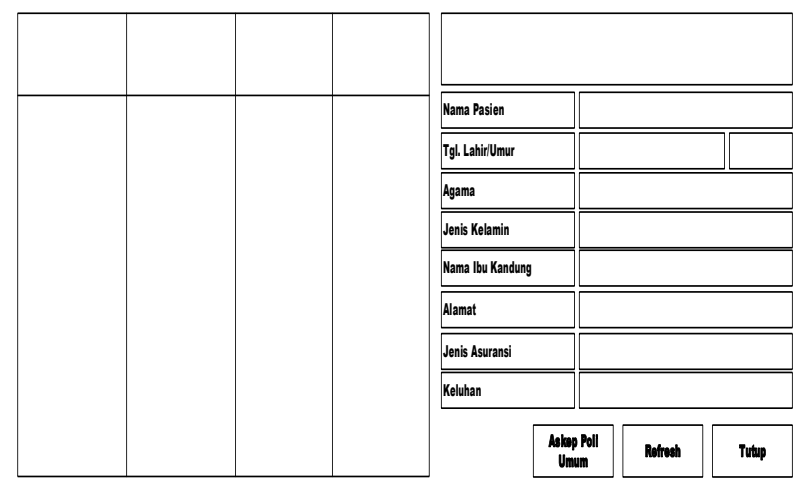

Gambar 16. Rancangan Antarmuka Poli Umum

i. Rancangan Antarmuka Poli MTBS

Rancangan antarmuka Poli MTBS digunakan untuk menampilkan data data yang ada pada poli MTBS.

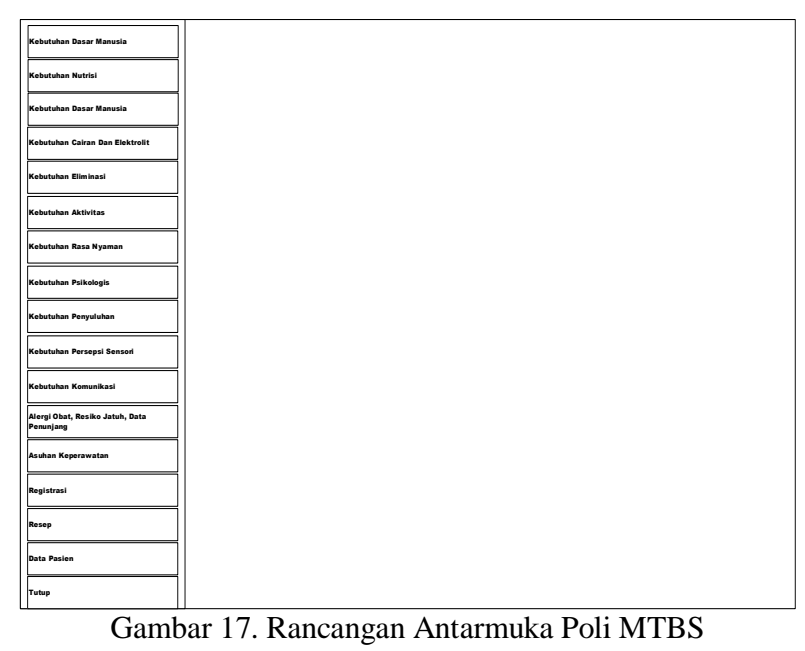


j. Rancangan Laporan

Rancangan Laporan digunakan untuk menampilkan laporan dan mencetak laporan.

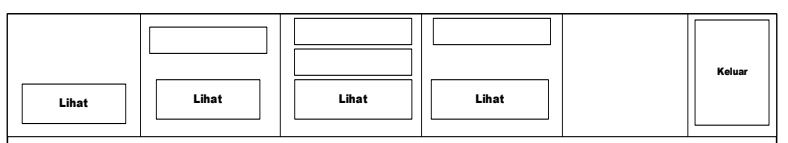

Gambar 18. Rancangan Laporan

\subsection{Implementasi Sistem}

Tahap implementasi adalah tahap penciptaan perangkat lunak, tahap kelanjutan dari kegiatan perancangan sistem. Tahap ini merupakan tahap system siap untuk dioperasikan, yang terdiri dari penjelasan mengenai lingkungan implementasi dari implementasi program.

\section{a. Implementasi Antarmuka Perangkat Lunak}

a. Tampilan Menu Login

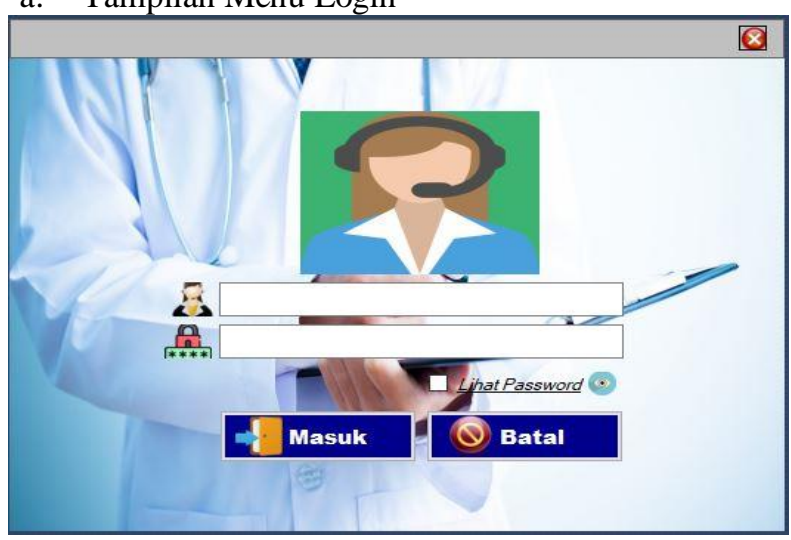

Gambar 19. Form Menu Login

b. Form Tampilan Menu Utama

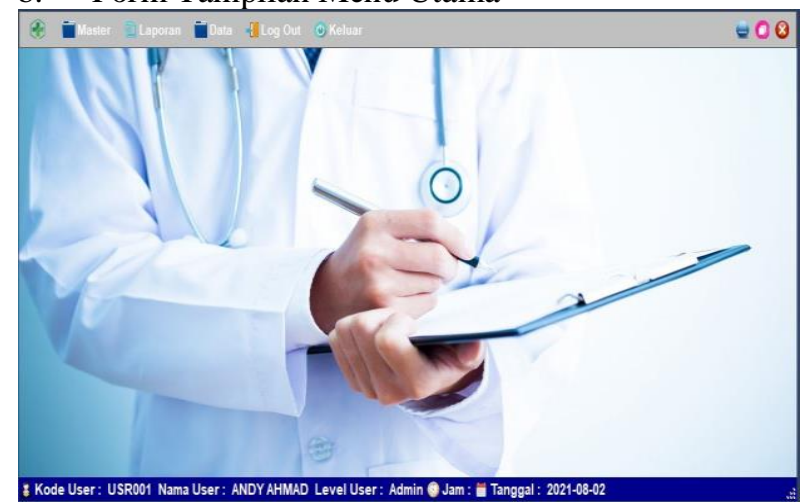

Gambar 20. Form Tampilan Menu Utama

c. Tampilan Input Data User

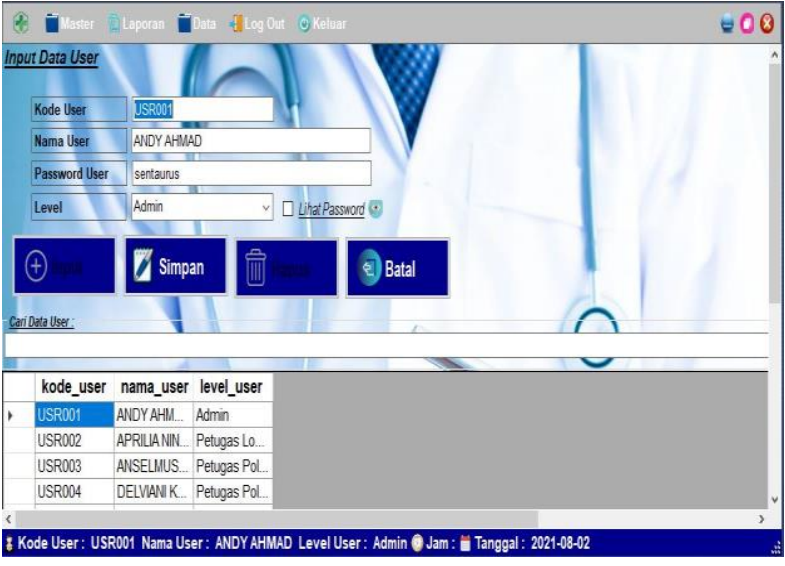

Gambar 21. Form Input Data User

d. Tampilan Input Data ICD 10

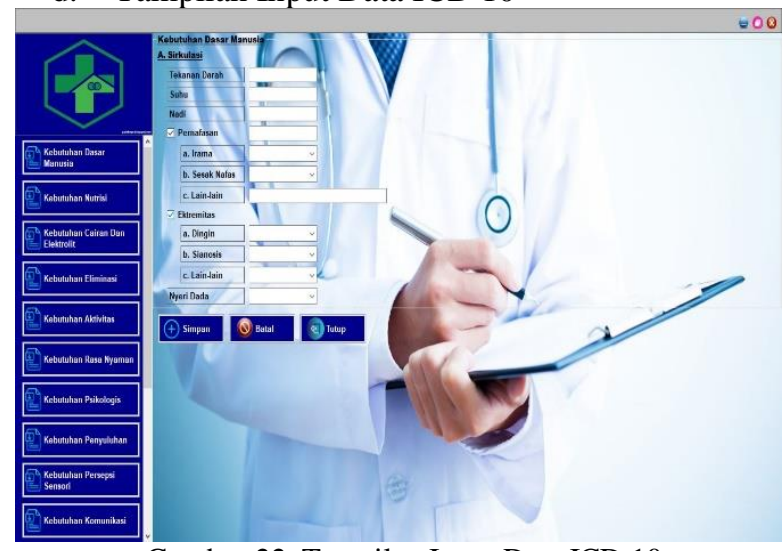

Gambar 22. Tampilan Input Data ICD 10

e. Tampilan Input Data Kunjungan Baru

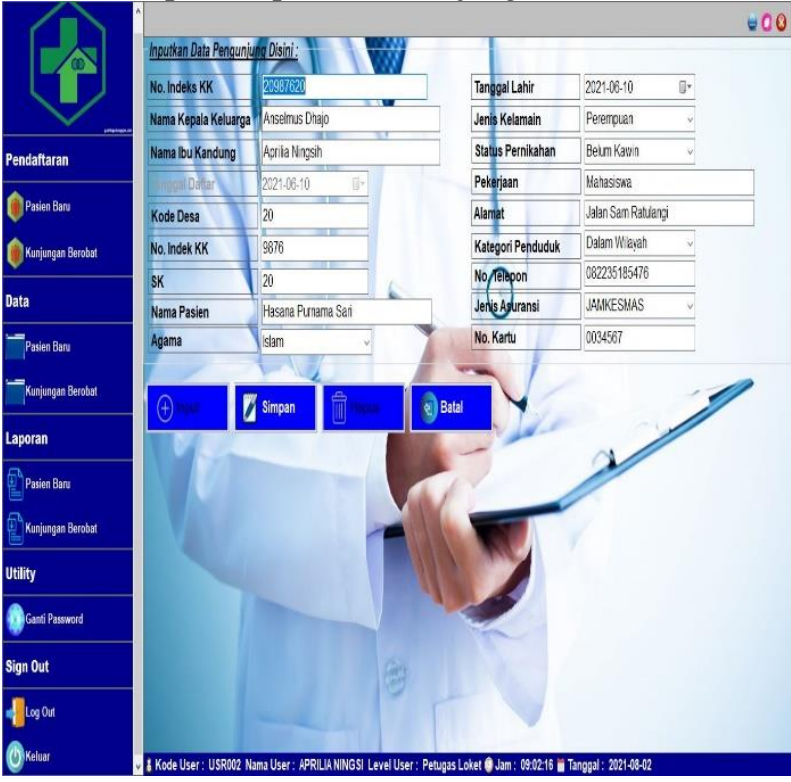

Gambar 23. Tampilan Input Data Pasien Kunjungan Baru 


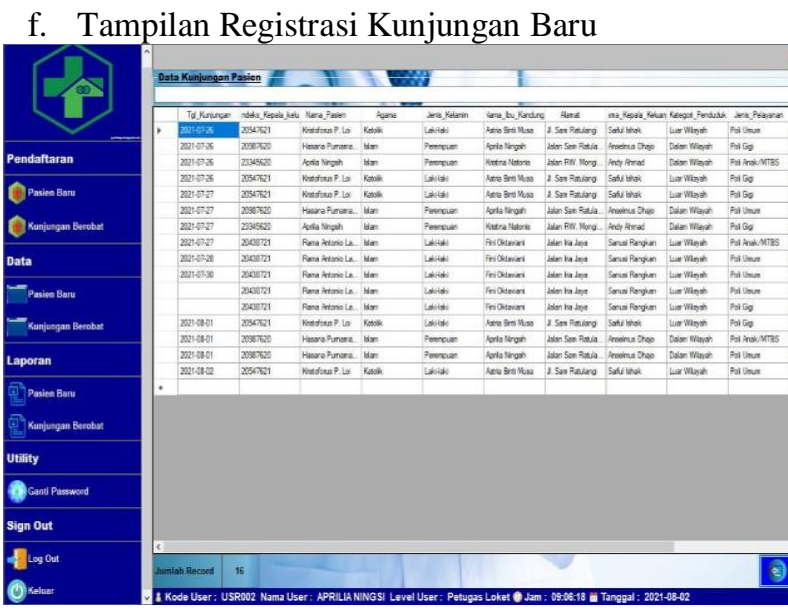

Gambar 24. Tampilan Registrasi Kunjungan Baru

g. Tampilan Input Data Kunjungan Pasien

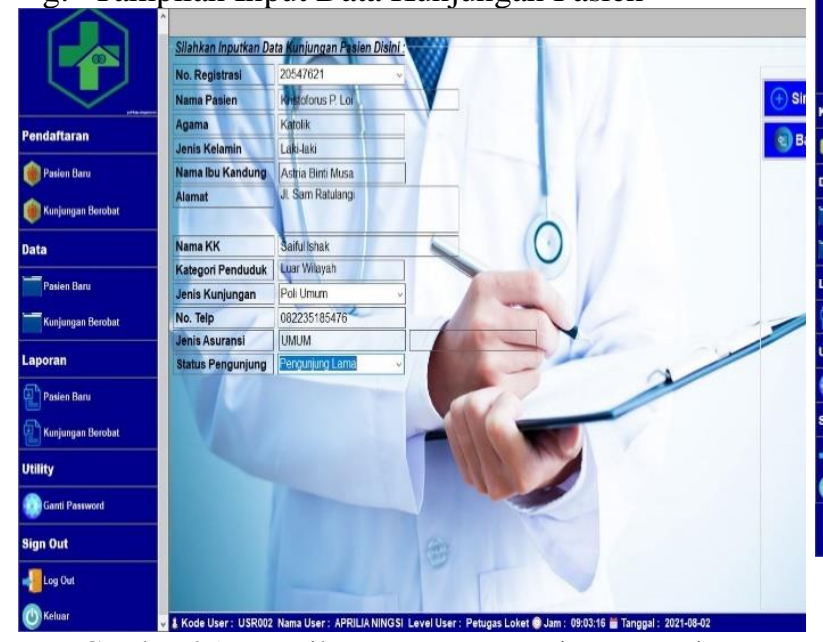

Gambar 25. Tampilan Input Data Kunjungan Pasien

h. Tampilan Registrasi Kunjungan Berobat

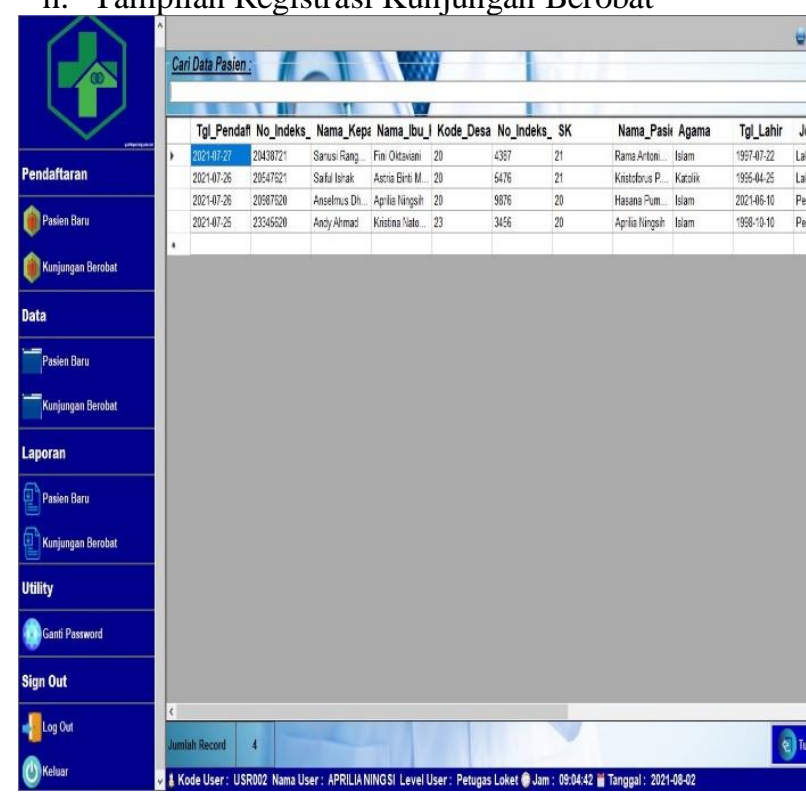

Gambar 26. Tampilan Registrasi Kunjungan Berobat

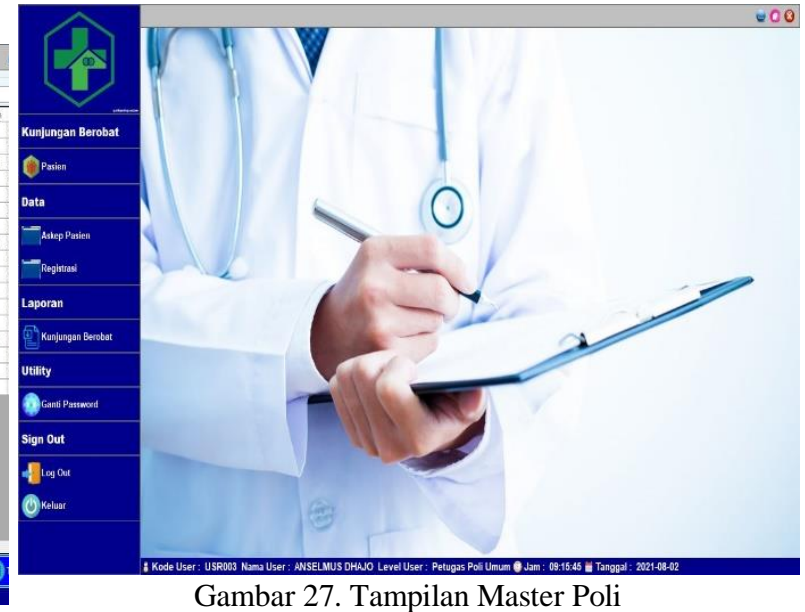

Gambar 27. Tampilan Master Poli

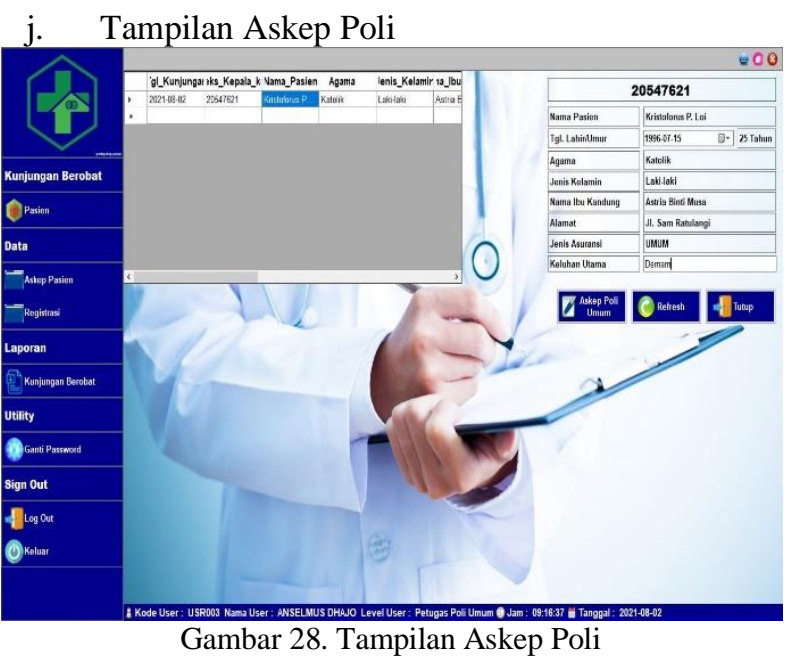

k. Tampilan Registrasi Poli
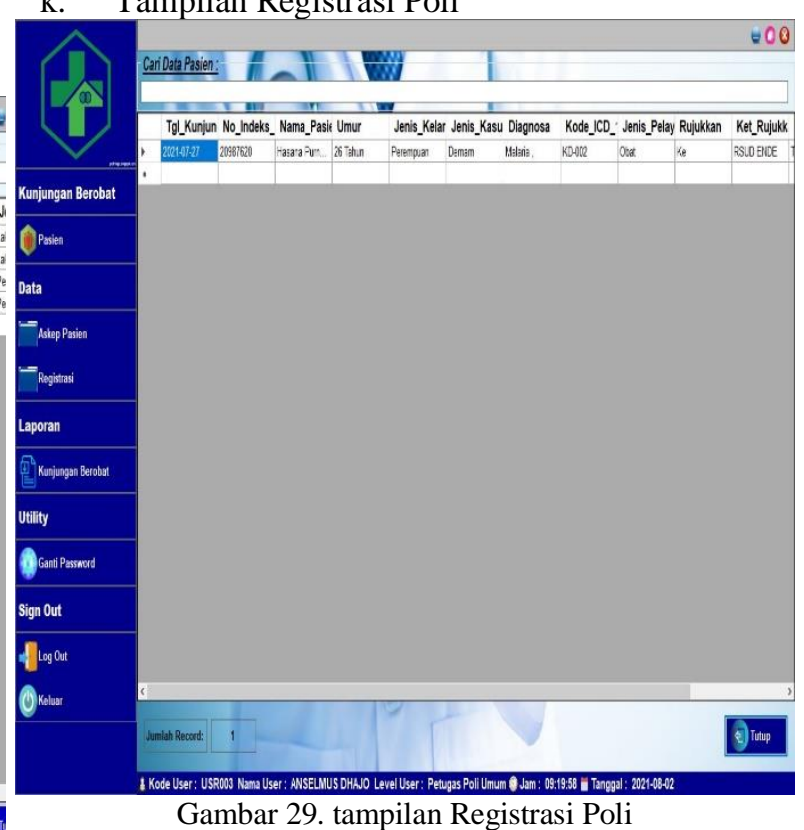

i. Tampilan Master Poli 
1. Tampilan Laporan Harian Poli Umum

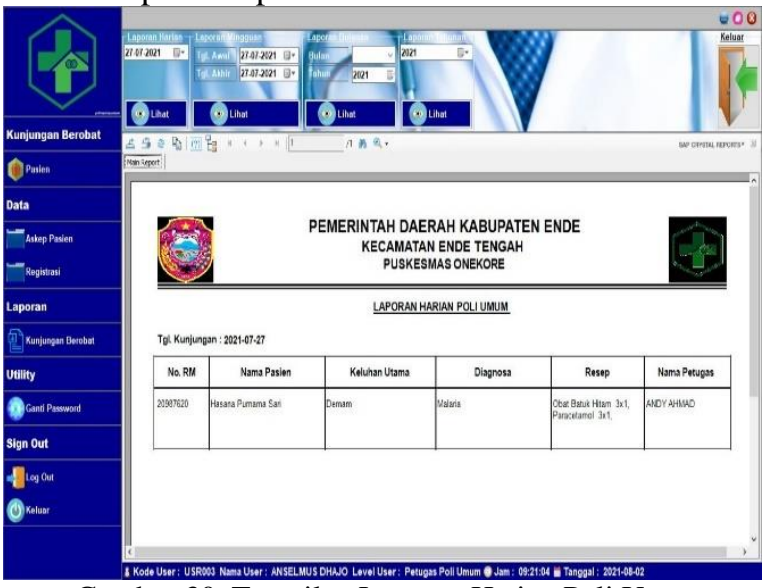

Gambar 30. Tampilan Laporan Harian Poli Umum

m. Tampilan Tahunan Kunjungan Pasien

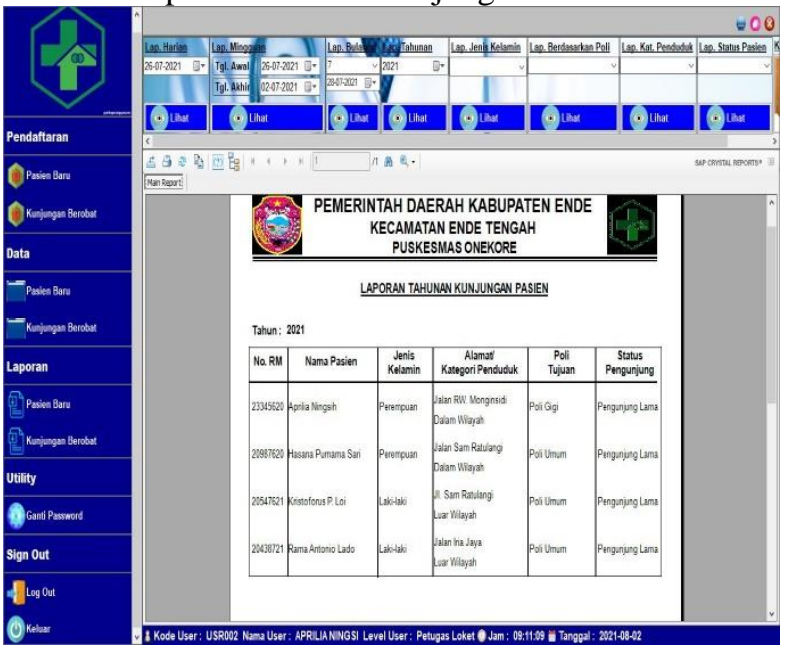

Gambar 31. Tampilan Tahunan Kunjungan Pasien

n. Tampilan Utility
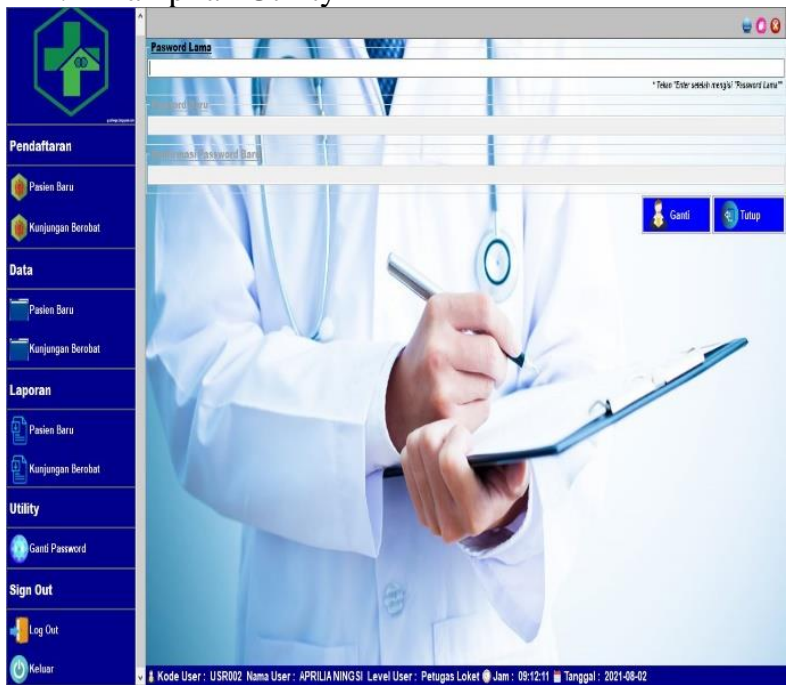

Gambar 32. Tampilan Utility

\section{Kesimpulan}

Berdasarkan pembahasan yang telah diuraikan dari bab-bab sebelumnya, dapat diambil beberapa kesimpulan yang berkaitan dengan sistem informasi rekam medis, yaitu membangun sistem informasi rekam medis berbasis komputer dapat membantu meningkatkan proses pelayanan kesehatan kepada pasien, yang jauh lebih cepat dan praktis dibandingkan dengan proses manual, memudahkan proses pencatatan identitas pasien pada saat pendaftaran dan tersimpan didalam database, pencarian rekam medis pasien oleh petugas tidak memakan waktu yang lama karena sudah menggunakan sistem pelayanan Kesehatan, mempercepat pengambilan obat oleh petugas dikarenakan resep obat langsung ditampilkan oleh system, memudahkan proses pembuatan laporan pasien oleh petugas, baik laporan harian, bulanan dan tahunan. Adapun saran-saran yang dapat digunakan peneliti lain untuk pengembangan perangkat lunak yang sudah dibuat, yaitu menambahkan fitur sms gateway pada loket pendaftaran, menambahkan form untuk poli-poli yang belum ada disistem, menambah fitur back up data.

\section{Referensi}

[1] I. Tanjung, "Perancangan Sistem Informasi Rekam Medis Terpadu Dalam Upaya," J. Intra-Tech, vol. 1, no. 1, pp. 43-54, 2017.

[2] A. Prasetyo, M. S. Azis, and R. M. Jomin, "Perancangan sistem informasi rekam medis pada puskesmas jomin berbasis web," vol. 13, no. 2, pp. 31-38

[3] F. Muhammad and S. L. Putri, "Jurnal Teknologi Informasi dan Komunikasi STMIK Subang, Oktober 2017 ISSN: 2252 4517," Sist. Inf. Pengolah. Data Pegawai Berbas. Web (Studi Kasus Di Pt Perkeb. Nusant. Viii Tambaksari), no. April, pp. 1-23, 2017.

[4] P. Andrianto, "Sistem Informasi Pelayanan Kesehatan Berbasis Web di Puskesmas,” vol. 2017, pp. 47-52, 2017. 